\title{
RET Inhibitor DS-5010
}

National Cancer Institute

\section{Source}

National Cancer Institute. RET Inhibitor DS-5010. NCI Thesaurus. Code C158093.

An orally bioavailable selective inhibitor of wild-type, fusion products and mutated forms, including gatekeeper mutations, of the proto-oncogene receptor tyrosine kinase rearranged during transfection (RET), with potential antineoplastic activity. Upon oral administration, DS-5010 selectively binds to and inhibits the activity of RET. This results in an inhibition of cell growth of tumors cells that exhibit increased RET activity. RET overexpression, activating mutations, and fusions result in the upregulation and/or overactivation of RET tyrosine kinase activity in various cancer cell types; dysregulation of RET activity plays a key role in the development and progression of these cancers. 